\title{
Calcipotriene/betamethasone dipropionate foam: primary evidence supporting its use in patients with psoriasis vulgaris. A narrative review
}

\author{
Joanna Narbutt ${ }^{1}$, Rafał Czajkowski ${ }^{2}$, Aleksandra Lesiak ${ }^{1}$, Witold Owczarek ${ }^{3}$, Adam Reich ${ }^{4}$, Jacek C. Szepietowski ${ }^{5}$ \\ 'Department of Dermatology, Paediatric Dermatology and Oncology, Medical University of Lodz, Lodz, Poland \\ ${ }^{2}$ Clinic of Dermatology, Sexually Transmitted Diseases and Immunodermatology, Faculty of Medicine in Bydgoszcz, \\ Nicolaus Copernicus University in Torun, Poland \\ ${ }^{3}$ Department of Dermatology, Military Institute of Medicine, Warsaw, Poland \\ ${ }^{4}$ Department of Dermatology, University of Rzeszow, Rzeszow, Poland \\ ${ }^{5}$ Department of Dermatology, Venereology and Allergology, Wroclaw Medical University, Wroclaw, Poland
}

Adv Dermatol Allergol 2021; XXXVIII (5): 727-733

DOI: https://doi.org/10.5114/ada.2021.110062

\begin{abstract}
Psoriasis vulgaris is a chronic, immune-mediated disorder, which has a substantial impact on all aspects of patients' quality of life. In most patients, the disease is mild to moderate and is successfully treated with topical agents. The most common therapy involves a vitamin $\mathrm{D}_{3}$ analogue (calcipotriene) in combination with a synthetic corticosteroid (betamethasone dipropionate). The aerosol vehicle (foam) with softening properties is another formulation of this combination drug, apart from ointment and gel, expanding the therapeutic options available to patients with psoriasis. The article describes the pharmacokinetic and pharmacodynamic properties of calcipotriene/betamethasone dipropionate foam. The results of the key randomised clinical studies investigating the efficacy, including patients' quality of life and safety of the foam versus ointment, gel and either active ingredient in foam vehicle are presented. In addition, the results of a study on maintenance treatment with calcipotriene/betamethasone dipropionate foam as well as reports on real-world use of this medicine in patients with psoriasis, are discussed.
\end{abstract}

Key words: psoriasis vulgaris, calcipotriene, betamethasone dipropionate, foam, topical administration.

\section{Introduction}

Psoriasis vulgaris is a chronic inflammatory skin disease. Psoriatic lesions can be small and confined to a small area, or they can cover large areas of the body. The disease has a substantial impact on all aspects of patients' quality of life. In most patients (approximately $80 \%$ ), lesions are mild to moderate [1]. According to epidemiological studies, the prevalence of psoriasis in the adult population ranges between $0.09 \%$ and $11.4 \%$, while in most developed countries, prevalence is between $1.5 \%$ and $5 \%$. The disease imposes a significant burden on both the healthcare system and society in general [2].

Among drugs recommended by the Polish Dermatological Society in the therapy of mild psoriasis of the body, the most common treatment involves a $D_{3}$ vitamin derivative - calcipotriene (Cal) in combination with a syn- thetic glucocorticoid - betamethasone dipropionate (BD). A combination of calcipotriene and betamethasone dipropionate has a more potent effect than either constituent alone [3]. Currently, preparations containing Cal/BD are available in three different formulations: ointment, gel and foam. Cal/BD ointment and gel, which have been registered first, have well-documented efficacy in the topical treatment of psoriasis [4, 5]. However, psoriasis is not adequately controlled in a significant number of patients, as therapeutic success depends not only on the drug efficacy, but also on the patient adherence, which is contingent on satisfaction with treatment. Regular use of topical medications is greatly affected by treatment vehicle, which may be found difficult to accept by patients (as too greasy, smelling unpleasant or time-consuming to apply) and the onset of treatment effect. The prolonged

Address for correspondence: Prof. Adam Reich MD, PhD, Department of Dermatology, University of Rzeszow, 2 Szopena St, 35-055 Rzeszow, Poland, phone: +48 605076 722, e-mail: adi_medicalis@go2.pl

Received: 13.06.2021, accepted: 22.06.2021. 
onset of action may discourage patients from using topical drugs regularly [6, 7]. The aerosol foam vehicle with emollient properties applied once daily, has been developed to expand the available therapeutic options in the topical treatment of psoriasis. Even though the Cal/BD concentration in foam is the same as in ointment or gel, the novel formulation of the drug determines its unique properties, which translates into clinical outcomes.

\section{Cal/BD foam pharmacokinetics and pharmacodynamics}

The efficacy of topical therapy depends, in particular, on the skin penetration of active ingredients and thus their bioavailability. After the evaporation of propellants, active substances may either remain in the solution to create a supersaturated environment or crystallise. Cal/BD foam and ointment formulations were compared for the ability of active ingredients to penetrate the skin. Crystals were absent for at least $26 \mathrm{~h}$ in the supersaturated Cal/ BD solution created by aerosol foam, while both calcipotriene and betamethasone crystals appeared immediately after application of ointment [8]. The skin penetration and bioavailability of Cal and BD from aerosol foam and ointment formulations were determined by in vitro and ex vivo assays, respectively. Administration of the final Cal/BD foam formulation led to significantly higher levels of Cal $(p=0.001)$ and $\mathrm{BD}(p=0.002)$ in the pig ear skin compared with ointment. It was also demonstrated in ex vivo conditions that a more significant amount of Cal and BD diffused into the skin from the supersaturated solution of foam compared with ointment [9].

There are significant pharmacodynamic differences between various Cal/BD formulations despite the same dose of both ingredients. The degree of skin blanching (vasoconstriction assay) is a measure of the potency of a corticosteroid and its ability to diffuse into the skin [10]. Phase I clinical trials demonstrated that Cal/BD foam had enhanced vasoconstrictor potency compared with Cal/BD ointment ( $p=0.001)$ and moderately potent corticosteroid ointments: fluocinolone acetonide $(p<0.001)$ [11] and hydrocortisone butyrate $(p<0.001)$ [12]. Simultaneously, the degree of skin blanching with Cal/BD foam was similar to BD ointment and $\mathrm{BD}$ foam ( $p=0.30$ and $p=0.83$, respectively) and significantly lower compared with very potent corticosteroids, such as clobetasol propionate cream $(p<0.001)[11,12]$.

Table 1. Methodology of key randomized clinical efficacy and safety trials of Cal/BD foam in patients with psoriasis

\begin{tabular}{|c|c|c|c|c|c|c|}
\hline Study & Study design & Duration & $N$ & Main inclusion criteria & Treatment arms (n) & Primary endpoint \\
\hline $\begin{array}{l}\text { Lebwohl } \\
2016[13]\end{array}$ & $\begin{array}{l}\text { Phase II, } \\
\text { randomized, DB, } \\
\text { parallel-group, } \\
\text { multicenter }\end{array}$ & 4 weeks & 302 & $\begin{array}{c}\text { Age } \geq 18 \text { years } \\
\text { At least 'mild' disease* } \\
\text { BSA } \leq 30 \% \text { (trunk, limbs and } \\
\text { scalp) } \\
\text { mPASI } \geq 2 \text { (trunk and/or } \\
\text { limbs) }\end{array}$ & $\begin{array}{l}\text { Cal/BD foam qd (100) } \\
\text { Cal qd (101) } \\
\text { Foam vehicle qd (101) }\end{array}$ & \multirow[t]{4}{*}{$\begin{array}{l}\text { Treatment success: } \\
\text { proportion of } \\
\text { patients who were } \\
\text { 'clear' or 'almost } \\
\text { clear' with } a \geq 2 \\
\text { grade improvement } \\
\text { in PGA }\end{array}$} \\
\hline $\begin{array}{l}\text { Koo } 2016 \\
{[14]}\end{array}$ & $\begin{array}{l}\text { Phase II, } \\
\text { randomized, IB, } \\
\text { parallel-group, } \\
\text { multicenter }\end{array}$ & 4 weeks & 376 & $\begin{array}{c}\text { Age } \geq 18 \text { years } \\
\text { At least 'mild' disease* } \\
\text { BSA } 2-30 \% \\
\text { mPASI } \geq 2 \text { (trunk and/or } \\
\text { limbs) }\end{array}$ & $\begin{array}{l}\text { Cal/BD foam qd (141) } \\
\text { Cal/BD ointment qd (135) } \\
\text { Foam vehicle qd (49) } \\
\text { Ointment vehicle qd (51) }\end{array}$ & \\
\hline $\begin{array}{l}\text { PSO-FAST } \\
(2015)[15]\end{array}$ & $\begin{array}{l}\text { Phase III, } \\
\text { randomized, DB, } \\
\text { parallel-group } \\
\text { multicenter }\end{array}$ & 4 weeks & 426 & $\begin{array}{c}\text { Age } \geq 18 \text { years } \\
\text { At least 'mild' disease* } \\
\text { BSA } 2-30 \% \\
\text { mPASI } \geq 2 \text { (trunk and/or } \\
\text { limbs) }\end{array}$ & $\begin{array}{l}\text { Cal/BD foam qd (323) } \\
\text { Foam vehicle qd (103) }\end{array}$ & \\
\hline $\begin{array}{l}\text { PSO-ABLE } \\
\text { (2017) [16] }\end{array}$ & $\begin{array}{l}\text { Phase III, } \\
\text { randomized, IB, } \\
\text { parallel-group, } \\
\text { multicenter }\end{array}$ & 12 weeks & 463 & $\begin{array}{c}\text { Age } \geq 18 \text { years } \\
\text { Mild-to-severe disease }{ }^{\star} \\
\text { BSA 2-30\% (trunk, limbs) } \\
\text { mPASI } \geq 2 \text { (trunk and/or limbs) }\end{array}$ & $\begin{array}{l}\text { Cal/CD foam qd (183) } \\
\text { Cal/BD gel qd (188) } \\
\text { Foam vehicle qd (47) } \\
\text { Gel vehicle qd (43) }\end{array}$ & \\
\hline $\begin{array}{l}\text { PSO-LONG } \\
(2020)[18]\end{array}$ & $\begin{array}{l}\text { Phase III, } \\
\text { randomized, DB, } \\
\text { parallel-group, } \\
\text { multicenter }\end{array}$ & $\begin{array}{l}4 \text { weeks } \\
\text { open-label } \\
\text { lead-in phase } \\
52 \text { weeks } \\
\text { randomized } \\
\text { maintenance } \\
\text { phase }\end{array}$ & 650 & $\begin{array}{c}\text { Age } \geq 18 \text { years } \\
\text { At least 'mild' disease* } \\
\text { BSA } 2-30 \% \\
\text { mPASI } \geq 2 \text { (trunk and/or } \\
\text { limbs) }\end{array}$ & $\begin{array}{c}\text { Lead-in phase: Cal/BD } \\
\text { qd (650) } \\
\text { Randomized } \\
\text { maintenance phase: } \\
\text { Cal/BD proactive } \\
\text { treatment biw (272) } \\
\text { Cal/BD reactive treatment } \\
\text { biw (273) }\end{array}$ & $\begin{array}{l}\text { Time to first relapse } \\
\text { defined as PGA } \\
\text { score at least } \\
\text { mild in patients } \\
\text { previously 'clear' or } \\
\text { 'almost clear' }\end{array}$ \\
\hline
\end{tabular}

${ }^{*}$ According to PGA; Cal - calcipotriol $50 \mu \mathrm{g} / \mathrm{g}, B D$ - betamethasone $0.5 \mathrm{mg} / \mathrm{g}$ as dipropionate, biw - twice a week, BSA - body surface area, DB - double blind, IB - investor blind, MPASI - modified Psoriasis Area and Severity Index, $N$-number of participants, $n$ - number of participants in the treatment arm, PGA - Physician's Global Assessment, qd - every day. 


\section{Cal/BD foam efficacy in clinical studies}

The efficacy of a 4-week treatment with Cal/BD foam was determined in controlled phase II and phase III studies, which involved a total of approximately 1,100 patients with psoriasis vulgaris (Table 1) [13-15]. The primary endpoint in these studies was the rate of treatment success defined as at least a two-step improvement on the five-point physician's global assessment (PGA) of disease severity scale at week 4 . In practice, this meant achieving 'clear' skin for patients with the baseline PGA of mild and 'clear' or 'almost clear' skin for patients with the baseline PGA of moderate or severe.

In a phase II study, Lebwohl et al. compared the efficacy of Cal/BD foam versus monotherapies with Cal and $B D$ in the same vehicle [13]. The study recruited adult patients with at least moderate psoriasis of the trunk and limbs or psoriasis of the scalp. At week $4,45.0 \%$ of Cal/BD foam patients achieved treatment success compared with $14.9 \%$ of patients treated with Cal foam alone $(p<0.001)$ and $30.7 \%$ of patients treated with BD foam alone $(p=0.047)$. Treatment success of the scalp psoriasis with Cal/BD foam was significantly greater than with Cal foam (53.0\% vs. 35.6\%; $p=0.021$ ), but not BD foam $(47.5 \% ; p=0.45)$. Mean modified psoriasis area and severity index (mPASI) score improved in all groups from baseline, with statistically significant differences between Cal/BD foam versus both Cal foam and BD foam ( $p<0.001$ for either comparison) [13].
Another phase II study by Koo et al. compared the efficacy of Cal/BD foam with Cal/BD ointment in patients with psoriasis of the limbs and trunk [14]. It showed that $54.6 \%$ of patients using Cal/BD foam achieved treatment success compared with $43.0 \%$ of those using Cal/ BD ointment ( $p=0.025)$. Patients using Cal/BD foam achieved significantly lower mPASI score at week 4 compared to patients using Cal/BD ointment. Furthermore, a more significant proportion of patients using Cal/BD foam achieved a $50 \%$ or a $75 \%$ reduction in mPASI score than ointment-treated patients. However, the difference between the groups was not statistically significant (Table 2) [14].

A phase III study, PSO-FAST, compared Cal/BD foam with foam vehicle (placebo). Patients with at least mild severity psoriasis of the trunk and limbs were enrolled [15]. At week 4, treatment success was achieved in 53.3\% of patients using Cal/BD foam versus $4.8 \%$ of those using foam vehicle alone $(p<0.001)$. A reduction in mPASI score was observed at week 1 of Cal/BD treatment versus no active regimen. At week 4 of Cal/BD foam treatment versus vehicle, both a significantly higher mean reduction in mPASI score (71.9\% vs. $25.8 \% ; p<0.001)$ and a substantially higher proportion of patients with a decrease in mPASI score by at least $75 \%$ and $50 \%$ were reported (Table 2) [15].

The efficacy of Cal/BD foam was also assessed versus Cal/BD gel in a 12-week phase III study, PSO-ABLE (Table 1) [16]. The study involved patients with mild to

Table 2. Efficacy of Cal/BD foam in the key phase II and III randomized clinical trials in patients with psoriasis

\begin{tabular}{|c|c|c|c|c|c|c|c|c|}
\hline \multirow[t]{2}{*}{ Study } & \multirow[t]{2}{*}{ Comparison } & \multirow{2}{*}{$\begin{array}{c}\text { Assessment } \\
\text { time point }\end{array}$} & \multicolumn{2}{|c|}{ Treatment success* } & \multirow{2}{*}{$\begin{array}{l}\text { Difference in } \\
\text { mean mPASI } \\
(95 \% \mathrm{Cl})\end{array}$} & \multirow{2}{*}{$\begin{array}{l}\text { Proportion of } \\
\text { patients achiev- } \\
\text { ing mPASI75 }\end{array}$} & \multirow{2}{*}{$\begin{array}{c}\text { Proportion of } \\
\text { patients achieving } \\
\text { mPASI50 }\end{array}$} & \multirow{2}{*}{$\begin{array}{l}\text { Difference in mean } \\
\text { intensity of itch on } \\
\text { VAS }^{\S}(95 \% \mathrm{Cl})\end{array}$} \\
\hline & & & Rate & $\begin{array}{c}\text { OR } \\
(95 \% \mathrm{Cl})\end{array}$ & & & & \\
\hline \multirow[t]{2}{*}{$\begin{array}{l}\text { Lebwohl } \\
2016 \\
{[13]}\end{array}$} & $\begin{array}{c}\text { Cal/BD } \\
\text { foam vs. Cal } \\
\text { foam }\end{array}$ & 4 weeks & $\begin{array}{l}45.0 \% \\
\text { vS. } \\
14.9 \%\end{array}$ & $\begin{array}{c}4.34 \\
(2.16-8.72) \\
p<0.001\end{array}$ & $\begin{array}{c}-2.03 \\
(-2.63 ;-1.43) \\
p<0.001\end{array}$ & $\begin{array}{c}49 \% \text { vs. } 18 \% \\
p<0.001\end{array}$ & $\begin{array}{c}80 \% \text { vs. } 44 \% \\
p \leq 0.003\end{array}$ & $\begin{array}{c}-15.3 \\
(-21.4 ;-9.1) \\
p<0.001\end{array}$ \\
\hline & $\begin{array}{c}\text { Cal/BD } \\
\text { foam vs. BD } \\
\text { foam }\end{array}$ & 4 weeks & $\begin{array}{l}45.0 \% \\
\text { vS. } \\
30.7 \%\end{array}$ & $\begin{array}{c}1.81 \\
(1.00-3.26) \\
p=0.047\end{array}$ & $\begin{array}{c}-1.19 \\
(-1.80 ; 0.59) \\
p<0.001\end{array}$ & $\begin{array}{c}49 \% \text { vs. } 34 \% \\
p=N S\end{array}$ & $\begin{array}{c}80 \% \text { vs. } 59 \% \\
p \leq 0.003\end{array}$ & $\begin{array}{c}-3.2 \\
(-9.4 ; 3.0) \\
p=0.31\end{array}$ \\
\hline $\begin{array}{l}\text { Koo } \\
2016 \\
{[14]}\end{array}$ & $\begin{array}{l}\text { Cal/BD } \\
\text { foam vs. } \\
\text { Cal/BD } \\
\text { ointment }\end{array}$ & 4 weeks & $\begin{array}{l}54.6 \% \\
\text { vS. } \\
43.0 \%\end{array}$ & $\begin{array}{c}1.7 \\
(1.1-2.8) \\
p=0.025\end{array}$ & $\begin{array}{c}-0.6 \\
(-1.1 ;-0.2) \\
p=0.005\end{array}$ & $\begin{array}{c}50.4 \% \text { vs. } \\
40.7 \% \\
p=0.052\end{array}$ & $\begin{array}{c}80.9 \% \text { vs. } 74.8 \% \\
\quad p=0.17\end{array}$ & $\begin{array}{c}-3.3(\mathrm{NR}) \\
p=\mathrm{NR}\end{array}$ \\
\hline $\begin{array}{l}\text { PSO- } \\
\text { FAST } \\
{[15,21]}\end{array}$ & $\begin{array}{c}\text { Cal/BD } \\
\text { foam vs. } \\
\text { foam } \\
\text { vehicle }\end{array}$ & 4 weeks & $\begin{array}{l}53.3 \% \\
\text { vS. } \\
4.8 \%\end{array}$ & $\begin{array}{c}30.3 \\
(9.7-94.3) \\
p<0.001\end{array}$ & $\begin{array}{c}-3.3 \\
(-3.9 ;-2.7) \\
p<0.001\end{array}$ & $\begin{array}{c}52.9 \% \text { vs. } 8.2 \% \\
p<0.001\end{array}$ & $\begin{array}{c}82.3 \% \text { vs. } 28.0 \% \\
p<0.001\end{array}$ & $\begin{array}{c}-20.4 \\
(-25.2 ; 15.6) \\
p<0.001\end{array}$ \\
\hline $\begin{array}{l}\text { PSO- } \\
\text { ABLE } \\
{[16,23]}\end{array}$ & $\begin{array}{c}\text { Cal/BD } \\
\text { foam vs. } \\
\text { Cal/BD gel }\end{array}$ & $\begin{array}{c}4 \text { weeks } \\
\text { Cal/BD } \\
\text { foam vs. } \\
8 \text { weeks } \\
\text { Cal/BD gel }\end{array}$ & $\begin{array}{c}38.3 \% \\
\text { vs. } \\
22.5 \%\end{array}$ & $\begin{array}{c}2.55 \\
(1.46-4.46) \\
p<0.001\end{array}$ & $\begin{array}{c}-0.59 \\
(-1.11 ;-0.06) \\
p=0.028\end{array}$ & $\begin{array}{c}52.1 \% \text { vs. } \\
34.6 \% \\
p<0.001\end{array}$ & - & $\begin{array}{c}-1.93 \\
(-5.78 ; 1.93) \\
p=0.33\end{array}$ \\
\hline
\end{tabular}

${ }^{*}$ Primary endpoint in all studies; ${ }^{\S}$ On $100 \mathrm{~mm}$ visual analogue scale (VAS) where 0 - none, 100 - most severe, Cal - calcipotriol $50 \mathrm{\mu g} / \mathrm{g}$, BD - betamethasone $0.5 \mathrm{mg} / \mathrm{g}$ as dipropionate, DLQI - Dermatology Life Quality Index, MPASI - modified Psoriasis Area and Severity Index, NR - not reported, NS - not significant, OR - odds ratio. 
severe psoriasis (according to PGA) who were amenable to topical therapy. The primary endpoint (treatment success) was defined in a similar way as in previous studies, and the principal analysis concerned the efficacy of 4-week foam treatment compared with 8-week gel treatment. The treatment success rate was by $15.8 \%$ higher among foam-treated patients compared with those treated with gel ( $p<0.001$; Table 2). Cal/BD foam provided superior efficacy across all three groups of baseline intensity of psoriatic lesions, namely mild (18.9\% vs. $0 \%)$, moderate (44.8\% vs. $31.6 \%$ ) and severe (50.0\% vs. $15.8 \%)$. The median time to treatment success with foam was 6 weeks and could not be determined for gel (as the 12 -week treatment period was too short to achieve the primary endpoint in $50 \%$ of patients in this group). Mean mPASI was lower in the Cal/BD foam group than in the gel group at each time point throughout the observation period. At the same time a reduction in mPASI score from baseline was significantly higher for 4-week Cal/BD foam treatment versus 8-week Cal/BD gel treatment $(p=0.028)$. Furthermore, foam treatment at week 4 versus gel treatment at week 8 markedly more often led to a statistically significant reduction in MPASI at all levels: $\operatorname{mPASI} 50(p=0.005), \operatorname{mPASI} 75(p=0.001)$ and mPASI90 ( $p=0.009)$ [16]. Superior efficacy of Cal/ $\mathrm{BD}$ foam in comparison with Cal/BD gel observed in the overall PSO-ABLE population was also maintained in a sub-group of patients with more severe disease manifestations. In a post hoc analysis from PSO-ABLE limited to patients with mild to severe psoriasis, a significantly greater proportion of Cal/BD foam-treated patients versus those treated with gel achieved MPASI75 at weeks 4 $(p=0.001), 8(p<0.001)$ and $12(p=0.006)$ and mPASI90 at weeks $4(p=0.02)$ and $8(p=0.012)$ [17].

The PSO-LONG study investigated the efficacy of long-term maintenance treatment of psoriasis with Cal/ $\mathrm{BD}$ foam versus vehicle (no active management; Table 1) [18]. Eligible for the study were patients who had previously achieved treatment success after 4 weeks of Cal/ BD foam treatment. Maintenance phase treatment involved Cal/BD foam (proactive management) or vehicle (reactive management) twice-weekly for 52 weeks on psoriatic lesions that had cleared during the open-label lead-in phase. The primary endpoint was the time to the first relapse defined as at least mild psoriasis on the fivepoint PGA scale. Upon the relapse, patients from either group received rescue treatment with Cal/BD foam once daily for 4 weeks. The PSO-LONG study results demonstrated that long-term treatment with Cal/BD foam was superior in prolonging time to the first relapse and reducing the number of relapses. Median time to the first relapse was 56 days in the proactive management group compared to 30 days in the reactive management group, and the risk of experiencing the relapse was reduced by $43 \%(\mathrm{HR}=0.57 ; 95 \% \mathrm{Cl}: 47-69 \% ; p<0.001)$. In addition, proactive management with Cal/BD foam tended to reduce the number of rebounds of increased severity compared to baseline (i.e. mPASI $\geq 125 \%$ of the baseline value). The number of patients with rebounds and an increase in $\mathrm{mPASI} \geq 125 \%$ was over four times lower in the proactive group versus the reactive group (4 vs. 17). Patients receiving long-term Cal/BD foam treatment had additional 41 days in remission (i.e. PGA $<2$ ) per year compared with the reactive group $(p<0.001)$. The positive health effects required a total of 37.5 additional Cal/ BD foam treatment days per year [18]. The dropout rate throughout the observation period of the PSO-LONG study was $53.9 \%$. However, this was within the expected range and had been reported previously in other longterm studies of Cal/BD [19].

\section{Cal/BD foam impact on patients' quality of life in clinical studies}

Determinants of quality of life in patients with psoriasis have been well established. The most troublesome symptom is an itch, and release from itch is an essential need for around $75 \%$ of patients with psoriasis [20]. The itch can disturb sleep and increase stress and feeling of stigmatisation, while the presence of visible skin lesions can impair patients' self-esteem and mood.

In clinical trials, the impact of Cal/BD foam treatment on itch was assessed using the Visual Analogue Scale (VAS). No statistically significant differences in patient-reported severity of itching on the VAS scale were observed at week 4 between the Cal/BD foam group and the groups treated with Cal/BD gel, Cal/BD ointment or BD foam [13, 14, 16]. However, 4-week Cal/BD foam treatment provided a significant reduction in the intensity of itching versus Cal foam alone $(p=0.002)$ [13]. Itch relief occurred relatively quickly: on day $5, a \geq 70 \%$ reduction from baseline was reported in $53 \%$ of patients treated with Cal/BD foam [21]. Pooled analysis of three 4-week trials indicated that Cal/ $\mathrm{BD}$ foam versus vehicle (no active treatment) led to rapid itch alleviation in the most affected sub-group, i.e. patients with baseline itch VAS > $40(n=484)$. In this sub-group, at least $70 \%$ itch reduction from baseline was achieved in $79.3 \%$ of foam-treated patients versus $38.1 \%$ of vehicle-treated patients $(p<0.001)$ [22]. Furthermore, pooled data from PSO-ABLE and PSO-FAST trials indicated that 4-week Cal/BD foam treatment demonstrated statistically significant superiority over reactive treatment in reducing itch-related sleep loss by at least $70 \%$ from baseline on the VAS scale $(p<0.001)$ [22]. There was no significant difference in reducing itch-related sleep loss between Cal/ BD foam and Cal/BD gel [23].

The quality of life of patients with psoriasis is commonly evaluated using the disease-specific Dermatology Life Quality Index (DLQI) questionnaire. DLQI has been used in over 40 different skin conditions. The score ranges between 0 and 30 (the higher the score, the more quality of life is impaired by a skin condition) [24]. 
The 4-week Cal/BD foam treatment provided a significant improvement in quality of life measured with DLQI compared to Cal foam $(p<0.001)$ or no active regimen $(p<0.001)$ [21] and did not differ from treatment with Cal/BD gel [23] or BD foam [13]. In the PSO-ABLE study, significantly more Cal/BD foam patients achieved DLQI scores, indicating no psoriasis-related impairment in quality of life (score 0 or $1 ; 45.7 \%$ ) at week 4 than Cal/BD gel patients (32.4\%; $p=0.013)$. A similar outcome was reported at week 12: patients treated with Cal/BD foam more frequently achieved DLQI scores indicating no quality of life impairment ( 0 or 1 ) than those treated with gel (60.5\% vs. 44.1\%; $p=0.003)$ [23].

The DLQI is not the only tool that can be used to assess the quality of life of patients with psoriasis. Another commonly used questionnaire is the Psoriasis Quality of Life Questionnaire-12 (PQoL-12), which comprises 12 questions to assess how the disease affects self-confidence, feeling of helplessness, embarrassment and emotional well-being, as well as the intensity of itching, irritation and pain of the skin. The PQoL-12 total score ranges from 0 to 120, where the higher score indicates the lower quality of life [25]. In the PSO-ABLE study, Cal/BD foam treatment demonstrated a significantly greater improvement in quality of life measured with the PQoL-12 questionnaire from baseline to week 4 versus Cal/BD gel $(p=0.029)$. The progress maintained until the end of the observation period, i.e. week 12 , but the difference between the groups was no longer statistically significant [23].

The quality of life of patients with psoriasis can also be assessed using generic questionnaires, such as the EQ-5D-5L. In the PSO-FAST study, Cal/BD foam significantly improved the general quality of life measured with the EQ-5D-5L Index at week 4 versus no active treatment $(p=0.005)$. At week 4 , a proportion of patients treated with Cal/BD foam who reported no pain/discomfort (one of the questionnaire domains) more than doubled from baseline, and was significantly higher compared with the group receiving no active treatment (68.4\% vs. $43.0 \%$; $p<0.001$ ). Mean changes in general quality of life after 4 weeks of Cal/BD foam treatment were the same regardless of the baseline severity of the disease (i.e. 0.08 for mild, moderate or severe psoriasis) [21]. In order to measure the treatment impact on the key problems related to psoriasis, a disease-specific version of the generic EQ-5D questionnaire was developed, which includes two additional dimensions: skin irritation and self-confidence (EQ-5D-5L-PSO). In the PSO-ABLE study, Cal/BD foam significantly improved the general quality of life measured with the EQ-5D-5L-PSO Index at week 4 versus Cal/BD gel $(p<0.001)$. At weeks 8 and 12 , quality of life improvement in the Cal/BD foam group continued to be higher than in the Cal/BD gel group, but the difference was not statistically significant [23].

As it is a chronic disease, any relapse or flare of psoriasis negatively affects patients' quality of life measured with both generic quality of life questionnaires (EQ-5D) or dermatology-specific questionnaires (DLQI, PQoL-12). Therefore, maintaining long-term remission is crucial to improving not only the clinical effects of treatment but also patients' quality of life $[26,27]$.

\section{Safety in clinical studies}

Topical treatment of psoriasis with corticosteroids and vitamin D analogues is commonly used. Still, their longterm application on large areas of the body can cause both topical and systemic adverse reactions. Randomised clinical trials demonstrated that 4-week Cal/BD foam treatment is well tolerated. No statistically significant differences in the frequency of occurrence of adverse events (AEs) or adverse drug reactions (ADRs) were reported during Cal/BD foam treatment versus active comparators (Cal) BD ointment, Cal/BD gel and each component as monotherapy in foam vehicle) or placebo [13-15]. According to a pooled analysis of 4-week studies, the most common AEs were reported in less than $1 \%$ of patients treated with Cal/BD foam. They included rhinitis, application-site pain and skin irritation [28]. Most AEs were mild to moderate. The rate of ADRs reported during Cal/BD foam treatment was low, ranging from $0.7 \%$ [14] to $7.6 \%$ [16]. Also, throughout 12-week Cal/BD foam treatment, most AEs were mild to moderate, and their rate was similar to that among Cal/BD gel patients [16]. Phase III clinical studies confirmed that either 4-week or 12-week Cal/BD foam treatment had no impact on calcium homeostasis [13-16].

Cal/BD foam was well tolerated during long term maintenance treatment. No new safety concerns in addition to those reported during short-term treatment were identified over a 52-week study. Adverse events were primarily mild, and their rate was low. AEs reported in $>5 \%$ of patients were upper respiratory tract infections, which were considered not related to the trial drug by the investigators. No cases of skin atrophy were reported. Proactive management with Cal/BD foam had no clinically relevant effect on the HPA axis or calcium metabolism. The rates of serious AEs and treatment-related AEs per 100 patient-years were similar in the proactive (Cal/BD) group and the reactive (vehicle) group (8.3 vs 7.9 and 2.8 vs. 4.5 , respectively) [18].

\section{Real-world clinical efficacy}

The positive effects of Cal/BD foam treatment are reflected in real-world clinical practice. A prospective observational study conducted in Germany determined the efficacy of 4-week Cal/BD foam treatment in 410 patients with psoriasis $[28,29]$. After 4 weeks of treatment with Cal/ BD foam, the severity of psoriasis, according to investigator global assessment (IGA), was significantly lower compared to baseline $(p<0.001)$. The most significant clinical benefit was reported in patients with severe psoriasis (IGA $=4$ at 
baseline). The rate of treatment success (defined as clear/ almost clear and at least 2-step improvement in the IGA score) was almost two times higher in this sub-group than in the overall population (43\% vs. $24 \%$ ). The 4-weeks Cal/BD foam treatment resulted in a significant reduction in PASI, IGA and the affected body surface area (BSA) from baseline ( $p<0.001$ for each comparison). In addition, after 4 weeks of treatment with Cal/BD foam, $43 \%$ of patients stated that psoriasis had no influence on their quality of life (DLQI = 0/1) compared to $10 \%$ at baseline [29]. Furthermore, a prospective study conducted in Spain determined satisfaction with Cal/BD foam among psoriatic patients with BSA at $<30 \%$. After 4 weeks of treatment with Cal/BD foam, about $84 \%$ of patients were at least satisfied with its ability to prevent or relieve symptoms, according to the Treatment Satisfaction Questionnaire for Medication (TSQM-9). Most patients (over $80 \%$ ) thought the aerosol foam was easy or very easy to apply [30].

In clinical practice, most physicians recommend Cal/ $\mathrm{BD}$ foam in the treatment of mild to moderate psoriasis. However, the German study demonstrated that also patients with severe psoriasis could benefit from Cal/ BD foam treatment. About $16 \%$ of patients had already received systemic therapy before. Despite the failure of systemic therapies in the past, those patients benefited from treatment with Cal/BD foam, as only $5.8 \%$ of patients terminated it prematurely due to treatment failure [29].

\section{Conclusions}

Randomised clinical trials demonstrated that a fixed combination of calcipotriene and betamethasone dipropionate in foam vehicle is effective in the treatment of psoriasis vulgaris. Its efficacy is superior to ointment and gel formulation for most endpoints related to a reduction in the severity of psoriasis, while maintaining a good safety profile. Rapid onset of action accompanied by high acceptability of foam formulation among patients can translate into better adherence and, consequently, higher efficacy of treatment in real-world clinical practice. The results of real-world studies are consistent with those of clinical trials and confirm that Cal/BD foam is effective over the entire range of severity of psoriasis - as the first-choice drug in the therapy of mild to moderate psoriasis or adjunctive treatment in systemic therapy of severe psoriasis. PSO-LONG study results confirmed that proactive management with Cal/BD foam can provide more extended remission periods compared with traditional reactive management (in which treatment is administered only after lesions appear). This can be considered a milestone for long-term psoriasis management.

\section{Conflict of interest}

The authors declare no conflict of interest.

\section{References}

1. Menter A. Gottlieb A, Feldman SR, et al. Guidelines of care for the management of psoriasis and psoriatic arthritis. J Am Acad Dermatol 2008; 58: 826-50.

2. World Health Organization. (2016). Global report on psoriasis. World Health Organization. Available at: https:// apps.who.int/iris/handle/10665/204417 [Last accessed: 09.04.2021].

3. Reich A, Adamski Z, Chodorowska Z, et al. Psoriasis. Diagnostic and therapeutic recommendations of the Polish Dermatological Society. Part I: Mild psoriasis. Dermatol Rev 2018; 105: 225-43.

4. Fleming C, Ganslandt C, Guenther L, et al. Calcipotriol plus betamethasone dipropionate gel compared with its active components in the same vehicle and the vehicle alone in the treatment of psoriasis vulgaris: a randomised, parallel group, double-blind, exploratory study. Eur J Dermatol 2010; 20: 465-71.

5. Papp KA, Guenther L, Boyden B, et al. Early onset of action and efficacy of a combination of calcipotriene and betamethasone dipropionate in the treatment of psoriasis. J Am Acad Dermatol 2003; 48: 48-54.

6. Bewley A, Page B. Maximizing patient adherence for optimal outcomes in psoriasis. J Eur Acad Dermatol Venereol 2011; 25: 9-14.

7. Pink AE, Jalili A, Berg P, et al. Rapid onset of action of calcipotriol/betamethasone dipropionate cutaneous foam in psoriasis, even in patients with more severe disease. J Eur Acad Dermatol Venereol 2019; 33: 1116-23.

8. Lind $M$, Nielsen KT, Schefe LH, et al. Supersaturation of calcipotriene and betamethasone dipropionate in a novel aerosol foam formulation for topical treatment of psoriasis provides enhanced bioavailability of the active ingredients. Dermatol Ther 2016; 6: 413-25.

9. Hollesen Basse L, Olesen M, Lacour JP, et al. Enhanced in vitro skin penetration and antipsoriatic effect of fixed combination calcipotriol plus betamethasone dipropionate in an innovative foam vehicle. J Invest Dermatol 2014; 134: S33. abst 192.

10. McKenzie AW, Stoughton RW. Methods for comparing percutaneous absorption of steroids. Arch Dermatol 1962; 86: 608-10.

11. Queille-Roussel C, Bang B, Clonier F, Lacour JP. Enhanced vasoconstrictor potency of the fixed combination calcipotriol plus betamethasone dipropionate in an innovative aerosol foam formulation vs. other corticosteroid psoriasis treatments. J Eur Acad Dermatol Venereol 2016; 30: 1951-6.

12. Queille-Roussel C, Nielsen J, Lacour JP. Vasoconstrictor potency of fixed-dose combination calcipotriol $(50 \mu \mathrm{g} / \mathrm{g})$ and betamethasone dipropionate $(0.5 \mathrm{mg} / \mathrm{g})$ cutaneous foam versus other topical corticosteroids used to treat psoriasis vulgaris. J Dermatol Treat 2019; 30: 529-33.

13. Lebwohl M, Tyring S, Bukhalo M, et al. Fixed combination aerosol foam calcipotriene $0.005 \%$ (cal) plus betamethasone dipropionate $0.064 \%(\mathrm{bd})$ is more efficacious than cal or bd aerosol foam alone for psoriasis vulgaris: a randomized, double-blind, multicenter, three-arm, phase 2 study. J Clin Aesthet Dermatol 2016; 9: 34-41.

14. Koo J, Tyring S, Werschler WP, et al. Superior efficacy of calcipotriene and betamethasone dipropionate aerosol foam versus ointment in patients with psoriasis vulgaris: a randomized phase II study. J Dermatolog Treat 2016; 27: 120-7.

15. Leonardi C, Bagel J, Yamauchi P, et al. Efficacy and safety of calcipotriene plus betamethasone dipropionate aerosol foam 
in patients with psoriasis vulgaris - a randomized phase III study (PSO-FAST). J Drugs Dermatol 2015; 14: 1468-77.

16. Paul C, Stein Gold L, Cambazard F, et al. Calcipotriol plus betamethasone dipropionate aerosol foam provides superior efficacy vs. gel in patients with psoriasis vulgaris: randomized, controlled PSO-ABLE study. J Eur Acad Dermatol Venereol 2017; 31: 119-26.

17. Paul C, Leonardi C, Menter A, et al. Calcipotriol plus betamethasone dipropionate aerosol foam in patients with moderate-to-severe psoriasis: sub-group analysis of the PSO-ABLE study. Am J Clin Dermatol 2017; 18: 405-11.

18. Lebwohl M, Kircik L, Lacour JP, et al. Twice-weekly topical calcipotriene/betamethasone dipropionate foam as proactive management of plaque psoriasis increases time in remission and is well tolerated over 52 weeks (PSO-LONG trial). J Am Acad Derm 2021; 84: 1269-77.

19. Kragballe K, Austad J, Barnes L, et al. A 52-week randomized safety study of a calcipotriol/betamethasone dipropionate two-compound product (Dovobet/Daivobet/Taclonex) in the treatment of psoriasis vulgaris. Br J Dermatol 2006; 154: 1155-60.

20. Augustin M, Eissing L, Langenbruch A, et al. The German National Program on psoriasis health care 2005-2015: results and experiences. Arch Dermatol Res 2016; 308: 389-400.

21. Leonardi C, Bagel J, Yamauchi P, et al. The aerosol foam formulation of the fixed combination calcipotriene plus betamethasone dipropionate improves the health-related quality of life in patients with psoriasis vulgaris: results from the randomized PSO-FAST study. J Drugs Dermatol 2016; 15: 981-7.

22. Jalili A, Lebwohl M, Stein Gold L, et al. Itch relief in patients with psoriasis: effectiveness of calcipotriol plus betamethasone dipropionate foam. J Eur Acad Dermatol Venereol 2019; 33: 709-17.

23. Griffiths CE, Gold LS, Cambazard F, et al. Greater improvement in quality of life outcomes in patients using fixedcombination calcipotriol plus betamethasone dipropionate aerosol foam versus gel: results from the PSO-ABLE study. Euro J Dermatol 2018; 28: 356-63.

24. Cardiff University, School of Medicine. Department of Dermatology \& Wound Healing. Clinical Activities. The Dermatology Life Quality Index (DLQI). http://www.dermatology.org.uk/quality/dlqi/quality-dlqi.html [Last accessed: 09.04.2021].

25. Shankar V, Ghosh S, Ghosh K, Chaudhuri U. PASI and PQOL12 score in psoriasis: is there any correlation? Indian J Dermatol 2011; 56: 287-9.

26. Korman NJ, Zhao Y, Roberts J, et al. Impact of psoriasis flare and remission on quality of life and work productivity: a real-world study in the USA. Dermatol Online J 2016; 22: 13030.

27. Ming-Ann H, James L, Robert W, et al. Frequency, prevalence, and burden of flares on patients with moderate to severe psoriasis: a retrospective cross-sectional analysis. J Psoriasis Psoriatic Arthritis 2017; 2: 64-70.

28. Menter A, Gold LS, Koo J, et al. Fixed-combination calcipotriene plus betamethasone dipropionate aerosol foam is well tolerated in patients with psoriasis vulgaris: pooled data from three randomized controlled studies. Skinmed 2017; 15: 119-24.

29. Gerdes S, Krakor M, Anger T, et al. Prospective, observational, non-interventional, multicentre study on the efficacy and tolerability of a new calcipotriol/betamethasone aerosol foam (Enstilar(R)) in patients with plaque psoriasis under daily practice conditions. Dermatology 2017; 233: 425-34.

30. Velasco M, González-Fernández D, Rodriguez-Martín M, et al. Patient and physician satisfaction with calcipotriol and betamethasone dipropionate aerosol foam in the treatment of plaque psoriasis on the body. Actas Dermosifiliogr 2019; 110: 752-8. 